\title{
ANÁLISE DO PROCESSO INCLUSIVO EM UMA ESCOLA ESTADUAL NO MUNICÍPIO DE BAURU: A VOZ DE UM ALUNO COM DEFICIÊNCIA VISUAL' ${ }^{1}$
}

\author{
Eliza Oliveira Lippe* \\ Fabio de Souza Alves** \\ Eder Pires de Camargo***
}

RESUMO: A proposta de educação inclusiva do governo estadual de São Paulo baseia-se na adaptação curricular. O presente estudo teve por objetivo analisar a vOz do aluno com deficiência visual incluído na sala de aula regular. Utilizou-se, para análise dos dados, a Análise Textual Discursiva. Os resultados obtidos demonstraram que o aluno com deficiência visual está apenas inserido na sala de aula regular, e as políticas públicas pouco se atentam para a sua inclusão. Nesse sentido, observamos a necessidade de uma formação continuada dos professores da sala regular, não apenas para adequar suas metodologias, mas também para que eles se preocupem em dialogar com os professores especialistas, empregando as salas de recursos como um espaço de apoio.

Palavras-chave: Inclusão Educacional, Deficiência Visual, Ensino de Ciências.

\section{ANALYSIS OF INCLUSIVE PROCESS IN A STATESCHOOL IN THE MUNICIPALITY OF BAURU: THE VOICE OF A STUDENT WITH VISION IMPAIRMENT}

ABSTRACT: The proposal of inclusive education inthe state government of São Paulo is based on curriculum adaptation. This study aimed to analyse the voice of the student with vision impairment included in a regular classroom. Textual Discourse Analysis was used for data analysis.the The results showed that the student with vision impairment is simply located in the regular classroom, and public policies pay little heed to their inclusion. In this sense, we notice the need for regular classroom teachers ongoing formation, so that they can conform their procedures, and also develop a dialogue with expert teachers, using the resource rooms as a place for support.

Keywords: Inclusive Education, Vision Impairment, Science Teaching.

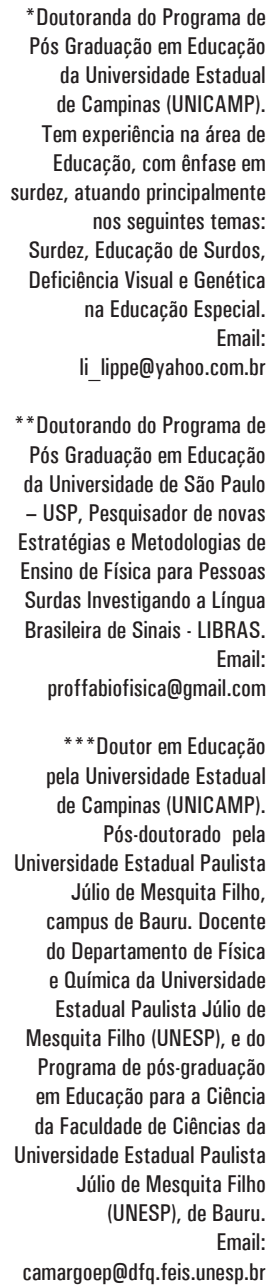

* Doutoranda do Programa de Pós Graduação em Educação da Universidade Estadual de Campinas (UNICAMP).

Tem experiência na área de Educação, com ênfase em surdez, atuando principalmente nos seguintes temas: Surdez, Educação de Surdos, Deficiência Visual e Genética na Educação Especial. Email:

li_lippe@yahoo.com.br

* *Doutorando do Programa de Pós Graduação em Educação da Universidade de São Paulo - USP, Pesquisador de novas Estratégias e Metodologias de Ensino de Física para Pessoas Surdas Investigando a Língua Brasileira de Sinais - LIBRAS. Email: proffabiofisica@gmail.com

*** Doutor em Educação pela Universidade Estadual de Campinas (UNICAMP). Pós-doutorado pela Universidade Estadual Paulista Júlio de Mesquita Filho, campus de Bauru. Docente do Departamento de Física e Química da Universidade Estadual Paulista Júlio de Mesquita Filho (UNESP), e do Programa de pós-graduação em Educação para a Ciência da Faculdade de Ciências da Universidade Estadual Paulista Júlio de Mesquita Filho (UNESP), de Bauru. Email:

camargoep@dfq.feis.unesp.br 


\section{INTRODUC̣ÃO}

A pesquisa aqui relatada insere-se na Dissertação de Mestrado intitulada "Ensino de Ciências e Deficiência Visual: uma investigação das percepções das professoras de Ciências e da sala de recursos em relação à inclusão”, cujo objetivo principal foi analisar as percepções das professoras em relação à inclusão dos alunos cegos, na sala de aula regular (LIPPE, 2010).

O intuito do trabalho foi, após a verificação de como se deu essa comunicação entre as professoras de Ciências e da sala de recursos, analisar de que forma o aluno com deficiência visual percebe sua participação na sala de aula regular. Propomos, também, discutir sobre os discursos e práticas da educação inclusiva, considerando a realidade apontada no município de Bauru, e sobre de que maneira os professores podem contribuir para que esse aluno participe de processos de aprendizagem.

A coleta de dados foi realizada no $9^{\circ}$ ano, ou $8^{\text {a }}$ série em uma Escola Estadual, no município de Bauru. O trabalho dividiu-se em duas partes, sendo que na primeira foi feita a observação da prática das docentes, em seus espaços escolares, tentando verificar se ocorria a inclusão dos alunos com deficiência visual. No segundo momento, foram realizadas as entrevistas com as professoras, para examinar, em seus discursos, quais as concepções de inclusão que elas possuíam. Dentro desse panorama, percebemos que os alunos se encontram em uma posição de dificuldade em sala de aula e, portanto, julgamos necessário ouvir a voz desse aluno, a fim de investigar como ele analisa seu próprio processo inclusivo.

Vygotsky (1997) faz referência à postura do professor, na sala de aula, salientando que ela determina ou não a aprendizagem dos alunos, por meio de mediações e trocas simbólicas, favorecendo o seu desenvolvimento. Diante disso, faz-se necessário que as escolas e principalmente os professores da sala regular se preparem para o atendimento aos alunos com necessidades educacionais especiais.

A inclusão escolar é uma inovação educacional que traz consigo uma proposta de abertura das escolas às diferenças. Porém, o ensino oferecido pela maioria delas, atualmente, não favorece tal revisão conceitual e pedagógica, uma vez que velhos modelos de ensino corroboram para a manutenção de medidas excludentes (BRASIL, 2003).

Ao fazer alusão à terminologia da escola inclusiva, Oliveira (2004) destaca que tal posicionamento exige da comunidade escolar uma reflexão crítica de seu papel e o repensar em oportunidades educacionais que propiciem a aprendizagem dos componentes curriculares por todos os alunos, e enfatiza que essa tarefa não é fácil e não se dá em curto período de tempo.

Ainda, segundo a autora, para que a escola se torne inclusiva, é preciso que sofra transformações de grandes proporções e em todas as direções (pedagógicas, administrativas, de formação em serviço, entre outras), buscando vencer antigos e atuais preconceitos existentes dentro dela.

Uma sala de aula inclusiva deve ser embasada nos princípios segundo os 
quais todas as crianças são capazes de aprender e fazer parte da vida escolar e comunitária. Nessa concepção, a diversidade não somente é valorizada, mas também deve ser considerada como um potencializador da união entre os membros de um grupo que favoreça a aprendizagem conjunta de todos os alunos.

Para Castaman (2006), o contexto escolar deve propiciar a inserção de todos os alunos, seja em ambiente público, seja privado, de modo acolhedor, com respeito, além de ofertar qualidade de ensino, independente da necessidade educacional especial que apresentem.

A inclusão educacional se assenta em uma proposta que reúne importantes valores simbólicos, compatíveis com a igualdade de oportunidades e direitos, oferecidos para todos os alunos, em um ambiente educacional adequado (BRASIL, 1998).

Observa-se que qualquer aluno, em algum momento de sua vida acadêmica, está sujeito a apresentar dificuldades, que podem ser traduzidas por necessidades educacionais. Caso isso aconteça, espera-se que seus professores, em geral, conheçam estratégias para contornar a situação, ajudando-o a superá-las. Porém, existem necessidades educacionais que requerem da equipe escolar uma série de recursos e apoios de caráter mais especializado, a fim de proporcionar ao aluno algumas estratégias para que ele acesse o currículo - são as chamadas de necessidades educacionais especiais.

Identificar as necessidades educacionais de um aluno como sendo especiais implica admitir que essas dificuldades são significativamente diferentes daquelas apresentadas por seus colegas, e que elas persistem após inúmeros esforços da equipe escolar para auxiliar o aluno a superá-las, por meio dos recursos e procedimentos comuns adotados pela escola. Nesses casos, especificamente, a concepção de especial está vinculada ao critério de diferença significativa do que se oferece normalmente para a maioria dos alunos da turma, no cotidiano da escola, ou seja, decorre de uma elevada capacidade ou de dificuldades para aprender, não necessariamente associadas a uma (ou mais) deficiência(s) (BRASIL, 1998).

Aranha (2004, p.51), focalizando o pensamento dos professores sobre a transição do processo inclusivo no cenário educacional brasileiro, ressalta:

\begin{abstract}
Nessa ocasião, os educadores puderam se manifestar com relação à proposta do governo federal bem como quanto às dificuldades que vivenciaram em sua realidade local. A proposta de implementação da educação inclusiva nos sistemas educacionais municipais e estaduais mostrou-se aceita por unanimidade, considerada consistente com a motivação e o interesse dos educadores presentes. Os participantes do encontro desvelaram dificuldades que têm sido encontradas no processo, como a necessidade de programas de formação continuada para professores, formalizadas em cada contexto educacional. (ARANHA, 2004, p.51).
\end{abstract}

O que a autora observa é factual e nos apoia no entendimento da escassez dos dados dos últimos censos escolares relacionados à formação do professor que atuará no atendimento aos alunos com deficiência, presentes nas salas regulares de ensino. Por conseguinte, a formação de profissionais da educação se constitui 
suporte à educação inclusiva e a formação continuada deve ter por base a realidade concreta na qual se dão as aprendizagens.

Com efeito, os professores da sala comum apontam como principais dificuldades para a realização da inclusão escolar a falta de formação especializada e de apoio técnico no trabalho com os alunos incluídos (PRIETRO, 2004).

Quando se trata da temática "formação de professor para o atendimento de alunos com deficiência",

[...] há de se contar com professores preparados para o trabalho docente que se estribem na perspectiva da diminuição gradativa da exclusão escolar e da qualificação do rendimento do aluno, ao mesmo tempo em que, dentro dessa perspectiva, adquiram conhecimentos e desenvolvam práticas específicas necessárias para a absorção de crianças com deficiência. (BUENO, 1999, p.18).

Portanto, levando em conta a demanda existente de alunos deficientes que estão sendo matriculados na escola comum, reafirmamos o compromisso dos professores com a organização de escolas inclusivas e os desafios postos à sua formação.

Ressalta-se a importância de verificar a questão familiar em relação à expectativa que os pais têm quanto ao nascimento do filho com deficiência (FRANCO, 2007) e a colaboração que eles dão, no que se refere ao auxílio na aprendizagem do filho com deficiência visual (SIGOLO, 2008).

Dados do censo de 2008 (BRASIL, 2009) acerca das matrículas dos alunos com deficiência em sala de aula regular possibilitam nossa compreensão sobre como está a realidade brasileira. Nota-se que a inclusão é um movimento em desenvolvimento, no Brasil, o que reforça os esforços pela democratização da escola, e, por conseguinte, de redemocratização social.

De acordo com tais dados, dos 375.775 estudantes com deficiência matriculados na rede regular de ensino, 352.638 (93,84\%) encontram-se inscritos na rede pública de ensino, enquanto apenas $23.137(6,16 \%)$ estão matriculados na rede privada.

Visto que essa é uma realidade crescente, algumas dúvidas são pertinentes quando o assunto é a inclusão de alunos deficientes visuais em sala de aula regular: de que forma o aluno com deficiência visual se vê na sala de aula? De que forma os professores podem melhorar a aprendizagem do aluno com deficiência visual em aulas de Ciências? Nesse sentido, o presente trabalho objetiva analisar o processo inclusivo na percepção do aluno com deficiência visual matriculado em sala regular do Ensino Fundamental na disciplina de Ciências.

\section{CONSIDERACְÕES METODOLÓGICAS}

A fim de identificar os sujeitos do trabalho, primeiramente foi realizado o levantamento junto à Diretoria de Ensino do município de Bauru, para verificarmos quantos e onde estavam matriculados os alunos com deficiência visual. No levantamento em questão, realizado em fevereiro/2009, constava a presença de 21 (vinte e 
um) alunos deficientes visuais matriculados na rede regular de ensino, no município de Bauru. Escolhemos aqueles que estudavam em uma escola estadual, no nono ano, que possuía a sala de recursos em deficiência visual. Após a análise do prontuário dos alunos e o telefonema para suas mães, percebemos que eles possuíam diferentes graus de acuidade visual, a saber: cegueira - que pode ser congênita ou adquirida - e baixa visão. Conforme o levantamento aludido, focamos as classes de dois alunos com cegueira congênita para a pesquisa in loco. Por não se encontrarem no mesmo período de ensino, decidimos trabalhar simultaneamente com os dois, a fim de observar o processo de ensino em ambos os períodos.

Os outros dois sujeitos da pesquisa foram a professora generalista da área de Ciências e a professora especialista da sala de recursos em deficiência visual. A primeira foi formada em Ciências Biológicas pela Universidade do Sagrado Coração de Jesus, no município de Bauru, e é docente do magistério público há 17 anos. Essa professora ingressou na escola analisada há aproximadamente 10 anos e lecionava, na ocasião da coleta de dados, para os dois períodos, ou seja, para a sala do aluno "Tales" e da aluna "Aline".

A segunda professora foi formada pela Universidade Estadual Paulista "Júlio de Mesquita Filho", no campus de Marília, em cuja grade curricular constava, até o ano de 2010, habilitações nas quatro deficiências (deficiência física, deficiência visual, deficiência auditiva e deficiência intelectual). Nessa instituição, a professora concluiu o curso de Pedagogia, com habilitação em Deficiência Visual, há 17 anos, tendo logo ingressado na escola analisada, na estruturação da sala de recursos.

Os nomes das escolas e dos sujeitos mencionados na pesquisa são fictícios, de maneira a preservar sua identidade. Destaca-se que os quatro sujeitos, isto é, as duas professoras e os responsáveis pelos dois alunos cegos, assinaram o termo de consentimento livre e esclarecido, autorizando a pesquisa e entrevista.

A coleta de dados se deu por meio de entrevista semiestruturada com os dois alunos. As entrevistas foram transcritas e submetidas a uma análise qualitativa. A opção por métodos qualitativos se deu pelo fato de trabalharmos com uma realidade que não pode ser facilmente quantificada, mas que possui significados e intencionalidade para os sujeitos consultados (BOGDAN; BIKLEN, 1994).

Além das entrevistas, outro instrumento que nos possibilitou constituir dados foi a observação das aulas. Lüdke e André (1986) ressaltam a importância da observação, na pesquisa qualitativa, afirmando que,

[...] na medida em que o observador acompanha in loco as experiências diárias dos sujeitos, pode tentar apreender a sua visão de mundo, isto é, o significado que eles atribuem à realidade que os cerca e às suas próprias ações. (LÜDKE; ANDRÉ, 1986, p.26).

As entrevistas foram utilizadas para aprofundar a questão central do trabalho, uma vez que essa técnica permite recolher dados descritivos, na linguagem do próprio sujeito, possibilitando desenvolver ideias sobre a maneira como ele interpreta os aspectos do mundo (BOGDAN; BIKLEN, 1994). 
Ainda em relação à entrevista e ao momento de sua realização, que sabemos serem etapas de grande importância dentro da pesquisa, Lakatos e Marconi (1991) afirmam:

[...] alguns autores consideram a entrevista como o Instrumento por excelência da investigação social, dando assim, oportunidade para a obtenção de dados que não se encontram em fontes documentais e que sejam relevantes e significativos. (LAKATOS; MARCONI, 1991).

O tratamento analítico dos dados foi feito por meio da elaboração das categorias e sistematização das falas dos alunos, com o uso da análise textual discursiva proposta por Moraes (2003; 2006). Segundo esse autor, a análise textual discursiva é descrita como um processo que se inicia com uma unitarização em que os textos são separados em unidades de significado. Depois desse processo, passa-se a fazer a articulação de significado semelhante, em um processo denominado categorização.

\section{RESULTADOS E DISCUSSÃO}

A seguir, apresentaremos as categorias de análise a respeito dos alunos cegos.

\section{Categoria 1: Interação dos alunos com deficiência visual e os outros alunos}

Essa categoria foi elaborada para apresentar os dados relacionados à interação entre os alunos com deficiência visual e os outros alunos, na sala de aula regular. Os relatos foram baseados na entrevista com os alunos cegos e na observação de suas posturas, na sala de aula da professora de Ciências.

Os estudantes relataram que nunca estudaram em escolas especiais para alunos com deficiência visual. Atualmente, eles se sentem bem na sala em que estudam, pois os alunos videntes são compreensivos e os ajudam no que podem. Por outro lado, o aluno "Tales" menciona que se sente desorientado na sala, por não saber o que está acontecendo e por não possuir muitos amigos, pois, infelizmente, como "Tales" teve problemas na infância e uma relação difícil com sua familia, houve uma negligência familiar na higiene e no cuidado com ele. Diante disso, ele apresentou outros problemas, além de ser cego: acabou perdendo alguns dentes (por falta de escovação), estava perdendo a audição (até o momento da coleta de dados, "Tales" já havia perdido a audição de um ouvido). Portanto, os colegas de sala não gostavam de ficar próximos a ele, devido às tais dificuldades.

Observa-se que os alunos com deficiência visual estão se adaptando à sala de aula regular, uma vez que, de acordo com a entrevista, eles se sentem perdidos na sala em alguns momentos, visto que não conseguem compreender os conteúdos ministrados, apesar do auxílio dos demais colegas videntes, em função de diversos fatores, tais como a ausência da máquina Braille e a falta de preparo dos professores generalistas no conhecimento clínico-pedagógico da deficiência visual. 
$\mathrm{Na}$ verdade, o desconhecimento e o preconceito dos alunos videntes e de suas famílias existem, de modo geral, na sociedade. Ou seja, muitas vezes as famílias se queixam na escola, afirmando que os alunos com deficiência visual atrapalham o andamento dos alunos videntes na sala de aula porque estes acabam tendo que os auxiliar nas atividades diárias na sala. Entretanto, a realidade mostrada no município de Bauru é diferente, pois tanto os alunos videntes quanto suas famílias, aparentemente, não demonstram ter preconceito em relação aos alunos deficientes visuais.

Nesse sentido, seguem abaixo algumas falas representativas dessa categoria com relação aos alunos com deficiência visual entrevistados. A letra "A" é referente às falas da aluna "Aline", e a letra "T" identifica as falas do aluno "Tales".

A-No CAIC até a $5^{a}$ série eu fiz aqui na escolinha aqui do lado e me dava super bem. Já no La Salles, que é até a $7^{a}$ série, não dava, era uma sala muito metida, não gostava de ajudar.

A-Ahbhb! De hoje eu me sinto muito bem, uma pessoa normal, porque nada impede de eu aprender e en acho que tenho meus direitos, e também com relação aos alunos eu me sinto bem... bem ajudada.

T-Eles não me ajudavam, eles apenas brigam comigo. Então, não sei o que poderia mudar pra eles se inteirarem mais comigo, eles não ficam perto, me deixam sożinho. Mas sempre tem um pra ajuda.

T-Abbhb! Sei lá, aprendi a viver na sala de aula, pois alguns alunos ficam comigo e outros não.

T- Acho que desse jeito não dá, porque eu fico que nem um bobão, lá. Entende?

\section{Categoria 2: Interação dos alunos com deficiência visual e os professores generalistas}

Essa categoria diz respeito à interação entre os alunos com deficiência visual e os professores da sala de aula regular (professores generalistas). Entende-se por professor generalista aquele que atua na sala de aula regular com os alunos com necessidades educacionais especiais, enquanto professor especialista é aquele especializado em atender aos alunos com deficiência, na sala de recursos.

Ambos os alunos relataram que quando estavam no primeiro ciclo, havia apenas uma professora na sala de aula, por isso se sentiam mais confortáveis. Já no segundo ciclo, com nove professores, eles se sentiam desconfortáveis, ao perceber que eram deixados de lado pelas professoras da sala regular, ou que elas solicitavam a eles que fizessem as atividades de aula na sala de recursos. Diante disso, os alunos se sentiam improdutivos na sala, não conseguindo participar e interagir a contento com o conteúdo e com as professoras generalistas, principalmente com a professora de Ciências, a qual não descrevia o que estava explicando no quadro.

Os alunos com deficiência visual colocaram algumas sugestões para as professoras, com o objetivo de tentar melhorar sua aprendizagem, como, por exemplo, descrever esquemas, sentar-se com os alunos, entre outras sugestões:

A-Eles tipo... tinham que sentar com os alunos, explicarpros alunos e, tipo assim, não fala tão rápido, explica pra eles e depois passa um método mais fácil que eu entenda e que entre na minha cabeça.

A-Tipo assim... a pessoa fala, explica como... abh... tipo, revolução russa, como foi, o que aconteceu lá, alguma 
coisa mais detalhado, mais expressado, mais descrito... e se puder algum material em Braille da sala de recursos.

A-Eu não participo...

A- Ahh, como eu me sinto? Eu me sinto uma pessoa inútil, dependo dos outros pra me ajudar.

A-Ai, penso que poderia conversar mais com meu colegas, fazer atividade em grupo, já ajudava bastante.

T-Sei lá... acho que descrever mais e usar mais o que tem na sala de recursos de Braille, assim, tipo, tem lá na sala várias coisas em Braille e fica difícil quando a gente não utiliza. Eu só tive uma professora boa que me dava bastante atenção, era de Educação Artística, na $5^{a}$ série, porque ela mostrava como faz pra estudar, en dizia pra ela que se en ficasse parado ali eu ia dormir e ela não me deixava parado, então ela sempre me dava atividade. Agora, as professores de hoje, todas as professoras, quando en comeco a escrever na máquina, elas me mandam parar dižendo que não me mandaram escrever nada, então eu digo assim: "Então, tá, beleza, eu vou dormir".

\section{Categoria 3: Relação entre a professora da sala de recursos e a professora de Ciências}

Os alunos com deficiência visual, no decorrer da entrevista, foram questionados em relação à comunicação entre a professora de Ciências e a professora da sala de recursos. Como eles estavam na mesma escola e no Ensino Fundamental Ciclo II, possuíam uma professora de Ciências que ministrava aula nos dois períodos e uma professora da sala de recursos que era responsável pelo apoio ao professor da sala de aula regular.

Eles enfatizaram que, se houvesse um diálogo maior entre elas, com certeza eles aprenderiam muito mais, mas afirmaram que esse diálogo ainda era pouco expressivo. Em relação à professora de Ciências, eles observaram que ela não se preocupava com eles, enquanto a professora da sala de recursos se preocupava mais com as famílias dos alunos cegos do que propriamente com a aprendizagem deles.

A-Ela poderia ser mais colega e deixar usar a máquina ou conversar com alguém... e com os conteúdos, ...ei lá... acho que sem tá em Braille fica difícil acompanhar, eu tô tentando, mas tá bem difícil, porque não entendo aquela história de átomo...

T-Então, se eles forem mais pacienciosos comigo, me ajudarem e me darem mais uma chance.

\section{Categoria 4: Utilização da máquina Braille e computadores na sala de aula}

Os alunos frisaram, na entrevista, querer usar mais a máquina Braille na sala de aula, mas infelizmente alguns professores generalistas não permitiam, por causa do barulho que já ocorria naturalmente na sala.

Em relação à utilização dos computadores que têm o software com programa de voz, tais como DOS-VOX e VIRTUAL VISION, na sala de aula, eles relataram que facilitaria a sua aprendizagem, visto que não fazem barulho e, com isso, não haveria a proibição por parte dos professores generalistas.

A questão da comunicação entre a professora de Ciências e a professora da sala de recursos foi evidenciada tanto pelos alunos com deficiência visual quanto pelas próprias professoras (quando entrevistadas, por ocasião na coleta de dados para a Dissertação). Salientamos que o contato que havia entre elas era 
superficial, não permitindo que discutissem os conteúdos científicos e os conteúdos que deveriam ser ensinados na sala de aula regular, pela professora generalista. Dito de outro modo, não havia, por exemplo, no Horário de Trabalho Pedagógico Coletivo (HTPC), um momento em que a professora de Ciências conseguisse se reunir com a professora da sala de recursos para poder mostrar os conteúdos científicos que estaria trabalhando com os alunos e solicitar o auxílio da colega, na transcrição do material em Braille ou na adaptação de recursos para poder ajudá-la a desenvolver o conteúdo na sala de aula.

Observamos, ainda, que os conteúdos científicos abordados pela professora de Ciências eram negligenciados, na medida em que ela não conseguia traduzir para o aluno o próprio conceito que estava ensinando, já que não empregava, em suas aulas, nenhum recurso adaptado, como a máquina Braille, recursos em alto relevo, materiais táteis, descrição minuciosa da aula e dos conteúdos ensinados.

Diante dessa situação, entende-se que a comunicação entre a professora de Ciências e a professora da sala de recursos deveria ocorrer para que o aluno cego não se sentisse perdido na sala de aula, ou seja, se houvesse uma comunicação efetiva entre as professoras, haveria recursos adaptados, materiais transcritos em Braille/português, uso de máquina Braille e/ou computador com leitor de voz, entre outros, o que não deixaria o aluno tão "perdido" na sala, ficando somente com a fala da professora de Ciências:

A- Na aula de Artes eu uso, mas tipo... a professora só não quis que eu escrevesse terça-feira passada, porque ela falava que já tava barulbo da classe, então vai fazer mais barulbo a máquina Braille...

A- Agora a professora é difícil, porque ela é brava, não deixa ninguém conversar, ai não consigo acompanhar a aula dela, de repente me perco no que ela tá falando e como ela não deixa usar a máquina Braille, acabo ficando sem matéria no caderno, sempre procuro fazer a tarefa, mas preciso que alguém me fale o que é de tarefa, entende, tia?

P-As professoras deixam você usar a máquina Braille?

T- A maioria não, porque faz muito barulho.

Apresentamos, a seguir, uma síntese dos principais resultados abordados pelas professoras e pelos alunos:

1. Acessibilidade à escola: na entrevista realizada com as duas professoras, enfocou-se a acessibilidade à escola como sendo um problema de ordem estrutural, como a falta de acessibilidade arquitetônica, isto é, a construção de rampas adaptadas, sala de aula para alunos com deficiência visual no piso térreo (pátio da escola) e banheiro adaptado.

Com isso, não podemos deixar de pensar na questão da acessibilidade ao currículo, que não é disponibilizado ao aluno cego, pois ele não tem acesso à informação em virtude de não ter o material adaptado em Braille. Devido à falta de materiais adaptados na sala de aula regular, os alunos com deficiência visual aca- 
bam sendo prejudicados, ficando à mercê da explicação audiovisual da professora generalista, que nem sempre é mais adequada e descritiva.

2. Formação inicial dos professores: O curso de formação inicial de muitos professores generalistas que atualmente estão na escola analisada não abordou assuntos relacionados à Educação Especial. Com isso, as discussões tornaram-se superficiais, uma vez que nos discursos desses professores eles apenas reivindicaram metodologias adequadas para ensinar os alunos com deficiência. Como observado nos Horários de Trabalho Pedagógico Coletivo (HTPC), os professores generalistas presentes na escola da pesquisa não discutiam as questões relacionadas à Educação Especial e, principalmente, temas relacionados à deficiência visual.

3. Falta de interesse por cursos de formação continuada: A falta de interesse por cursos de formação continuada na área de deficiência visual também foi enfocada pela professora de Ciências, pela professora da sala de recursos e pelos alunos com deficiência visual. Constatamos que há cursos oferecidos na rede estadual com esse enfoque, mas eles ocorrem em horários que são de difícil acesso aos professores. É preciso destacar que a maioria dos cursos de formação continuada do Ministério da Educação é oferecida na modalidade à distância, ou seja, os professores generalistas teriam condições de realizá-los a contento. Entretanto, o que observamos é que houve, por parte da professora de Ciências, uma "desculpa" para não realizar cursos de formação continuada, sobretudo cursos com a temática de deficiência visual, que é tão presente na escola em que ela trabalha.

4. Interação dos alunos com deficiência visual e a professora de Ciências: A interação entre os alunos com deficiência visual e a professora de Ciências era superficial, visto que ocorreram duas situações simultâneas, na sala de aula regular. $\mathrm{Na}$ primeira, a professora de Ciências não abordou os conteúdos científicos na sala de aula, pois ela apenas apresentou os conteúdos, sem descrevê-los minuciosamente. $\mathrm{Na}$ segunda, a professora não utilizou em suas aulas recursos adaptados da sala de recursos para os alunos com deficiência visual.

No decorrer da coleta de dados do trabalho de Mestrado, realizamos entrevistas com os alunos com deficiência visual, com as professoras generalista e especialista e com as duas mães dos alunos com deficiência visual, para verificarmos qual a visão que as famílias tinham em relação à inclusão dos alunos com deficiência, na sala de aula regular. Nesse sentido, observamos que as expectativas criadas pelas famílias no nascimento de um filho são contrariadas pela realidade, quando a criança nasce com alguma deficiência, visto que, muitas vezes, segundo Franco (2007), os pais reagem como se tivessem perdido um ente querido ou passado por algum trauma, e geralmente não estão preparados para lidar com uma criança "diferente".

Em decorrência, a família muitas vezes acaba se compadecendo e realiza as atividades por seus filhos, como foi verificado no caso de um dos alunos. Esse "auxílio" - que era realizar a atividade pelo aluno, pesquisar na internet as ativida- 
des pelo aluno, buscar por recursos no lugar do aluno - pode acabar prejudicando o desenvolvimento psicológico e cognitivo da criança, uma vez que impede a sua independência e autossuficiência.

Segundo Sigolo (2008), a colaboração entre a família e a escola tem sido vista como uma condição primordial para o desenvolvimento infantil e de adolescentes com deficiência. Ainda de acordo com a autora, as colaborações efetivas entre pais e professores originam o sucesso do aluno com deficiência na escola, propiciando condições para a criança efetivamente obter êxito na sua aprendizagem. Porém, tanto os pais quanto os professores devem reconhecer, perante a sociedade, suas responsabilidades partilhadas.

Sublinhamos que, no princípio da coleta de dados do Mestrado, notou-se uma dificuldade de adaptação da professora de Ciências com os alunos com deficiência visual. Em diversos momentos, ela pouco se preocupava com esses alunos, pois não utilizava outros recursos ou estratégias para auxiliá-los em sua aprendizagem, como, por exemplo, não levar para a sala material adaptado, em alto relevo, transcrito em Braille antes da aula.

Os professores generalistas, em sua maioria, foram formados em uma época em que pouco se falava em inclusão, as décadas de 1960, 70 e 80, quando os alunos com deficiência estavam presentes nas escolas especiais, que a priori não tinham a função de escolarização, apenas de socialização. Verificamos que alguns professores generalistas pouco se interessam pela temática da Educação Especial e, quando questionados a respeito, acabam por confessar que prefeririam que os alunos estivessem nas classes especiais e não nas salas regulares.

A proposta da nova política é a inclusão dos alunos com deficiência, em sala de aula regular, entretanto, essas escolas regulares, em sua maioria, foram construídas nas décadas de 60 e 70, e são escolas com escadas, banheiros pequenos, poucas rampas de acesso, semelhantes à escola que foi escolhida para a investigação relatada neste trabalho.

Quando observamos a prática de professores que atuam com alunos com deficiências, constatamos, principalmente, o fato de que eles não participam da elaboração das propostas curriculares quando se trata da inclusão dos alunos com deficiência, restringindo-se a ser meros aplicadores de projetos elaborados quanto à adaptação da proposta curricular para os alunos com deficiência. Mesmo assim, os professores devem proporcionar, em suas aulas, questões reflexivas, fazendo com que os alunos deficientes se tornem críticos dessa sociedade plena de preconceitos.

É importante entender as necessidades do aluno com deficiência visual na sala de aula, pois com o auxílio do professor especialista, o professor generalista pode conseguir executar o seu papel docente com maior competência.

$\mathrm{Na}$ leitura das considerações apresentadas por Vygotsky (1997), percebe-se que as posturas adotadas pelo professor em sala de aula determinam ou não a aprendizagem do aluno e, consequentemente, o seu desenvolvimento. Para o autor, o processo educacional deve possibilitar o estabelecimento de trocas interativas entre os seus personagens, de maneira que cabe ao professor favorecer formas de o aluno 
acessar o universo dos saberes sistematizados, concedendo grande parte do suporte necessário para a sua participação ativa no contexto sociocultural.

Particularizando essa ideia para a Educação Especial, o professor, no trato pedagógico com seus alunos, deverá realizar ações que contribuam para o desenvolvimento das funções psicológicas superiores dos alunos, atuando como um mediador, ou seja, como parceiro mais capaz, que possibilite a realização de atividades as quais o aluno ainda não possui condições para realizar autonomamente. Atuando desse modo, estará colaborando para o desenvolvimento potencial desses alunos, distanciando-se de concepções errôneas apresentadas comumente na relação com o deficiente, julgado como indivíduo de menor valia.

Atualmente, os cursos de licenciatura estão se reestruturando e incluindo, em suas grades curriculares, disciplinas relacionadas à inclusão, ou seja, eles serão formados com pelo menos alguma discussão teórica sobre esse tema.

No que concerne à mudança do currículo do Estado de São Paulo, observamos que, na visão das duas professoras, esta foi benéfica para o aprendizado dos alunos e por sistematizar os conteúdos em todas as escolas do Estado.

Não podemos deixar de mencionar o atraso da entrega dos materiais em Braille nas escolas, ou seja, os materiais referentes ao primeiro bimestre chegaram às escolas apenas no terceiro bimestre, o que acabou, em alguns momentos, sobrecarregando as professoras da sala de recursos, ao terem que transcrever os materiais em Braille e em tinta.

Por outro lado, a remuneração dos professores que trabalham com Educação Especial também é discutida em algumas pesquisas, ressaltando-se que não deve haver distinções salariais entre os professores generalistas e especialistas, visto que cada um está com grande sobrecarga de atividades.

Prieto (2004) destaca que

[...] a crescente demanda de alunos com deficiência nas classes comuns tem intensificado a necessidade de ampliação das produções teóricas que nos auxiliem a compreender as diferentes possibilidades de organização curricular e demais alterações recomendadas, exigidas ou passíveis de realização para melhor atender à diversidade de características de aprendizagem dos alunos. (PRIETO, 2004).

Existem, atualmente, poucas pesquisas acadêmicas que focam o diálogo entre os professores generalistas e especialistas. Contudo, é importante destacar que esse diálogo deveria ser constante entre eles, porque encontramos os alunos com deficiência sendo marginalizados e segregados na sala de aula comum, simplesmente pela falta de conhecimento do professor generalista sobre as necessidades dos alunos com deficiência. Sobre esse tema, as entrevistadas discordaram em suas colocações, visto que, de acordo com a professora generalista, havia uma interação entre elas, no sentido de que a generalista comunicava as suas atividades para a especialista, com antecedência, a fim de que ela providenciasse os materiais necessários para a aula. Por sua vez, a professora especialista afirmou que não havia ligação alguma entre ambas, pois a professora de Ciências era totalmente independente em suas atividades. 


\section{CONSIDERAC̣ÕES FINAIS}

Os trabalhos levantados em relação ao ensino de Ciência e a Educação Especial retratam que há poucas pesquisas na área da Educação Especial e inclusão. Nos textos analisados no decorrer da pesquisa de Mestrado, em um total de 31 trabalhos, há predomínio de pesquisas relacionando o ensino de Física com a deficiência visual, e poucas pesquisas nas outras áreas, como Biologia, Química e Matemática, e com outras deficiências, tais como a auditiva e a intelectual.

Portanto, esse é um campo que necessita de muitas investigações que sejam retornadas à comunidade de forma a esclarecer e compreender as dúvidas e angústias dos professores generalistas e especialistas. Todavia, enfatizamos a necessidade e a urgência em capacitar os professores generalistas para trabalharem com alunos com deficiência visual, pois, atualmente, existem mais de 40.000 alunos matriculados na rede regular de ensino, o que sugere que os professores que não foram formados na perspectiva da educação inclusiva devem fazê-lo agora para que o aprendizado do aluno não seja negligenciado na sala de aula regular.

Por fim, deve-se insistir que quando ocorrer a efetiva comunicação entre os professores generalistas e especialistas, haverá a inclusão e a participação efetiva na sala de aula regular pelos alunos com deficiência visual. A capacitação poderia começar a ocorrer na sala de recursos, nos HTPCs da escola, propondo discussões que façam os professores generalistas refletirem sobre a inclusão do aluno com deficiência visual.

\section{NOTAS}

${ }^{1}$ Conselho Nacional de Desenvolvimento Científico e Tecnológico (CNPq); Núcleo de Apoio ao Ensino de Ciências e Matemática de Ilha Solteira (NAECIM); Grupo de Pesquisa em Ensino de Ciências e inclusão escolar (ENCINE- www.fc.unesp.br/encine).

\section{REFERÊNCIAS BIBLIOGRÁFICAS}

ARANHA, M. S. F. Educação inclusiva: transformação social ou retórica? In: OMOTE, S. (Org.). Inclusão e intenção e realidade. Marília. Fundepe, 2004, p. 37-59.

BOGDAN, R.; BIKLEN, S. Investigação qualitativa em educação: uma introdução à teoria e aos métodos. Porto: Porto Editora, 1994.

BRASIL, Ministério da Educação. Censo Escolar, 2008, INEP, Brasília, INEP, 2009. Disponível em: <http://www.inep.gov.br/basica/censo/Escolar/Sinopse/sinopse.asp>. Acesso em: 10 dez. 2009.

- Procuradoria Federal dos Direitos do Cidadão. $O$ acesso de pessoas com deficiência às classes e escolas comuns da rede regular de ensino. Brasília: MPF/PFDC, 2003.

. Senado Federal. Constituição da República Federativa do Brasil de 1988, Brasília: Senado Federal, 1988. . Secretaria de Educação Fundamental. Secretaria de Educação Especial. Parâmetros curriculares nacionais: adaptações curriculares. Brasília: MEC/SEF/SEESP, 1998.

BUENO, J. G. S. Crianças com necessidades educativas especiais, políticas educacional e a formação de professores: generalistas ou especialistas? Revista de Educação Especial, Piracicaba, v. 3, n. 5, p. 7-25, set. 1999. 
CASTAMAN, A. S. Percursos e Discursos de Normalização na Educação Especial. Revista Divisa, Itapiranga, SC, v. 4, p. 23-30, 2006. Disponível em: < http://www.seifai.edu.br/artigos.php> Acesso em: 11 dez. 2009.

FRANCO, J. R. et al. Orientação educacional às famílias com deficiência visual. In: MANZINI, E. J. (Org.). Inclusão de alunos com deficiência na escola: os desafios continuam. Marília: ABPEE/FAPESP, 2007. LAKATOS, E. M.; MARCONI, M. A. Fundamentos de Metodologia Científica. São Paulo: Atlas, 1991. LIPPE, E. M. O. O Ensino de Ciências e deficiência visual: uma investigação das relações existentes entre os professores especialistas e generalistas no Ensino Fundamental em uma escola estadual no município de Bauru. 2010, 105 f. Dissertação (Mestrado em Educação para a Ciência) - Faculdade de Ciências, Universidade Estadual Paulista "Júlio de Mesquita Filho", Campus de Bauru, Bauru, 2010. LÜDKE, M.; ANDRÉ, M. Pesquisa em Educação: abordagens qualitativas, São Paulo: EPU, 1986.

MORAES, R. Uma tempestade de luz: a compreensão possibilitada pela análise textual discursiva. Revista Ciência \& Educação, São Paulo v.9, n.2, p.191-211, 2003.

; GALIAZZI, M. C. Análise textual discursiva: processo reconstrutivo de múltiplas faces. Revista Ciência \& Educação, São Paulo v.12, n.1, p.117-128, 2006.

OLIVEIRA, A. A. S. Flexibilizações e Adequacões Curriculares para Atendimento às Necessidades Educacionais Especiais. SINOP-MT: CEACD/UNEMAT; Editora UNEMAT, 2006.

PRIETO, R. G. Políticas de melhoria da escola pública para todos: tensões atuais. Disponível em: $<$ http:// www.educacaoonline.pro.br>Acesso em: 09 out. 2009.

SIGOLO, S. R. R. L; OLIVEIRA, A. M. L. A. Relação família-escola e o processo de inclusão escolar- subsídios para orientação família. In: MENDES, E.G.; ALMEIDA, M. A.; HAYASHI, M. C. P. I. (Org.). Temas em Educação Especial: conhecimentos para fundamentar a prática. Araraquara, SP: Junqueira \& Marin; Brasília, DF: CAPES-PROESP, 2008.

VYGOTSKI, L. S. Obras Escogidas V: Fundamentos de Defectologia. Madrid: Gráfica Rogar, 1997.

Data de Recebimento: 25/05/2011

Data de Aprovação: 23/08/2011

Data da Versão Final: 07/02/2012 